\title{
La reacción jurídica del Ecuador ante la Primera Guerra Mundial: de la neutralidad a la ruptura de relaciones
}

\author{
Dr. Farith Simon Campaña
}

\section{Resumen}

La Primera Guerra Mundial tuvo un impacto significativo en todo el mundo, en este trabajo se explora la forma en que esta conflagración impactó en las decisiones jurídicas del Ecuador, esto como un indicador de la relevancia que tuvo la primera gran guerra en nuestro país.

Palabras claves: Primera Guerra Mundial, Ecuador, legislación.

\begin{abstract}
World War I had a significant impact on all around the world, this paper explores how this conflagration struck the legal decisions of Ecuador as an indicator of the importance that the first great war for had our country.
\end{abstract}

Key Words: World War I, Ecuador, legislation.

\section{Sumario}

I. Introducción. II. Nos declaramos neutrales. 1. La "Ley Moratoria" y medidas económicas. 2. Restricciones de exportaciones. III. Ruptura de relaciones con Alemania. IV. iViva la paz! iGanamos la Guerra! A manera de Conclusión.

Doctor en Derecho por la Universidad de Salamanca, Doctor en Jurisprudencia, Abogado y Licenciado en Ciencias Jurídicas y Sociales por la Pontificia Universidad Católica del Ecuador. Decano y Profesor titular del Colegio de Jurisprudencia de la Universidad San Francisco de Quito. 


\section{Introducción}

En este trabajo exploro cuál fue la reacción, desde una perspectiva jurídica, del Ecuador ante la Primera Guerra Mundial. Esto implica una revisión de las decisiones de carácter normativo que se tomaron en el país entre julio de 1914 y enero de 1919. Como veremos nuestro país transitó desde una posición de "estricta neutralidad" (con cierta simpatía hacia Francia), a la ruptura de relaciones con Alemania, esto como un reflejo claro de su posición pro aliada, pero fundamentalmente pro norteamericana, que asumió posteriormente el país y que se mantuvo durante muchos años.

Para la elaboración de este trabajo se revisaron 1332 registros oficiales, distribuidos así: 618 de la administración Plaza (desde el No. 568, correspondiente al día 28 de julio de 1914, al 1186 de 30 de agosto de 1916, correspondiente al último RO publicado por esa administración); y 714 de la administración Baquerizo Moreno (desde el No. 1 de 1 de septiembre de 1916 hasta el No. 713 del 30 de enero de 1919, incluido el RO 866 de 11 de agosto de 1919 que contiene el Mensaje del Presidente de la República al Congreso Ordinario de 1919, donde se refiere a los hechos posteriores al fin de la Guerra y la posición ecuatoriana).

Es claro que desde una perspectiva militar el impacto en el país fue nulo, sin embargo, contribuyó a la reconfiguración de las relaciones internacionales del país que, antes de la conflagración, era fuertemente dependiente de las potencias económicas europeas y luego de los Estados Unidos. No obstante, el impacto más significativo fue el económico puesto que estos años condicionaron la economía del país, especialmente en lo referido a la moneda.

Al estallar la Primera Guerra Mundial el Ecuador vivía en segundo mandato presidencial de Leónidas Plaza Gutiérrez (1/09/1912 a 31/08/1916). Liberal, acusado por militantes proalfaristas y proandradistas de ser responsable de instigar los asesinatos de Eloy Alfaro y del general Julio Andrade'. Debido a ello tuvo que enfrentar una serie de insurrecciones, particularmente en la provincia de Esmeraldas, donde actuaban grupos guerrilleros encabezados por Carlos Concha; esto obligó a dirigir gran cantidad de sus recursos económicos para encarar lo que sucedía en el norte del país.

\footnotetext{
1 A la muerte del presidente Emilio Estrada en diciembre de 1911 inició un guerra civil que se prolongó hasta el año 1916, las fuerzas gubernamentales derrotaron a los insurgentes; los líderes rebeldes recibieron un armisticio y dejen el país, sin embargo la presión popular e indignación provocó la revocatoria de esta decisión, el Gral. Pedro Montero fue juzgado y condenado a dieciséis años de trabajos forzados, pero fue asesinado brutalmente por una turba en el mismo Tribunal de Justicia; por esto fue trasladado los restantes caudillos a Quito donde Eloy Alfaro también fue asesinado. Los dos contendores para la presidencia Laso y Andrade representaban la solución a los problemas. Andrade fue asesinado por un desconocido y Plaza fue electo Presidente.
} 
El conflicto terminó luego que Carlos Concha fue detenido y los rebeldes fueron amnistiados por el nuevo Presidente Alfredo Baquerizo Moreno (1/09/1916 al 31/08/1920), durante cuya presidencia terminó la Primera Guerra Mundial².

En 1914 comienza la crisis del cacao debido a la caída del precio de la "pepa de oro" en los mercados internacionales. Esta es una crisis que duró hasta 1925 con la casi desaparición de las plantaciones. El precio disminuyó de S/. 21 sucres a S/. 10 sucres, esto porque los tres mercados más importantes de la "pepa de oro"3 (Alemania, Francia e Inglaterra) prohibieron su importación. Además, incrementaron los costos de los fletes y seguros debido a la priorización que se dio al transporte de material bélico y se incrementó la oferta internacional de cacao.

Posteriormente las plantaciones fueron afectadas por la Monilla y la Escoba de Bruja que provocaron una disminución de la producción, al tiempo en el que el precio llegó a caer a S/. 5,75. Paralelamente se incrementaron los precios de las manufacturas importadas, lo cual llevó a que la moneda se devalúe en 2,25\%. Este proceso se dio pese al alivio momentáneo que se vivió entre 1918 y 1920 por el incremento del precio del cacao, de S/. 10,25 a S/. 20,75. Dicho incremento fue el resultado del crecimiento del mercado norteamericano, lo que significó el inicio de una dependencia, tanto política como económica, de los Estados Unidos, que desplazó a los países europeos.

Plaza y Baquerizo Moreno contribuyeron a la modernización institucional del país, especialmente Plaza, quien ejerció una significativa influencia en la vida nacional. La etapa liberal, en opinión de Enrique Ayala, es el "momento más relevante de formación del Estado Nacional"4. Sin embargo, estos gobiernos cedieron de forma significativa ante los intereses de la banca privada guayaquileña, inaugurando el período Plutocrático que finalizó con la revolución

2 Un interesante estudio de este período de la historia ecuatoriana, y el rol de los gobiernos liberales y en particular de Leónidas Plazo se puede leer en el estudio de Linda Alexander Rodríguez, publicado en la Revista Cultura, Volumen IX, número 26, septiembre-diciembre 1986, Quito, pp. 15-40. La autora considera que este período de la historia del Ecuador se caracterizó por el "regionalismo, autoritarismo, militarismo, y personalismo".

3 Producción y exportación de CACAO (informe Birch Rocher, Encuentro historia, p. 410)

1915796612

1916828828

1917900953

1918760289

1919750485

1920754481

1921832788

1922832788

1923606519

1924623456

1925540956 (hasta 1 de agosto)

4 Ayala Mora, E., "Política y Sociedad en el Ecuador Republicano 1830-1980"; publicado en Política y Sociedad: Ecuador 1830-1980, Tomo I, Corporación de Estudios y Publicaciones, Quito, 1980, (pp. 11-31), p. 17. 
juliana en 1925. Esto debido a que el presupuesto estatal dependía en gran parte de los impuestos que se cobraban por la exportación del cacao, de ahí la dependencia presupuestaria de los préstamos otorgados por los bancos costeños $^{5}$. Como veremos, la llamada "Ley Moratoria" se aprobó para favorecer a los bancos guayaquileños, en particular al Banco Comercial y Agrícola de Guayaquil de Francisco Urbina Jado.

En la época de Baquerizo Moreno se abolió la prisión por deudas ("apremio personal") y se estableció la jornada laboral en un máximo de 8 horas diarias y 6 días a la semana en todos los empleos ${ }^{6}$.

\section{Nos declaramos neutrales}

En la parte final del mensaje del Presidente Plaza al Congreso Ordinario de $1914^{7}$ se expresó la preocupación por el inicio de la guerra y el impacto económico, que a raíz de esta conflagración, afirmó el Presidente, se empezó a sentir en nuestro país:

En momentos de cerrar este Mensaje, ha llegado a nuestro país la nueva dolorosa de haber estallado en el Continente Europeo la guerra más terrible y vasta que registra la historia de los siglos y en la que, hasta este instante, aparecen comprometidas cinco naciones, sin que sea posible calcular la extensión posterior que ella pueda alcanzar.

Lamentamos profundamente que los países más cultos de la tierra se hayan visto en el caso de apelar al recurso de las armas para solucionar conflictos de su diplomacia; y hacemos votos porque cuanto antes termine esa inmensa conflagración, que tiene proyecciones mundiales, ya que sin poder evitarlo, todos los comercios, todas las finanzas, todas las industrias y todos los países del globo, van a sufrir, directa o indirectamente, las consecuencias de esa inmensa lucha armada, entre las naciones que regulan los intercambios internacionales.

En el Ecuador, ha repercutido en el acto el efecto de esa guerra; y debemos exponernos a la adopción de algunas medidas preventivas contra la seria gravitación que van a producir en nuestra situación económica, fiscal y particular, las hondas perturbaciones de los mercados europeos.

\footnotetext{
5 Alexander Rodríguez, L., "La política en el Ecuador, 1830-1925", publicado en la Revista Cultura Volumen IX, número 26, septiembre-diciembre 1986, Quito, p. 37.

6 Enrique Ayala Mora, De la Revolución Alfarista al Régimen Oligárquico Liberal (1895-1925), Nueva Historia del Ecuador, Volumen 9, Corporación Editora Nacional, Quito, 1983, (pp. 119-166), p. 159. 7 RO No. 579 de 11 de agosto de 1914, p. 1840.
} 
afectnosa cordialidad a que tuve el honor de referirme en mi Mensaje del año proximo pasado.

Poco tiempo después de estallar la Guerra Europen, el Pacífico occidental fue tentro de importantes operaciones navales. Ias escuadras de los países beligerantes se disputaban el dominio del océano, en defensa de sus rutas y mercados comerciales; $y$ aurique en nuestras aguas territoriales hicieron acto de presencia algunos escuadrones ingleses, alemanes y japoneses, tuvimos la fortuna de que en ellas no se produjeran hechos de armas.

Sin embargo, y no obstante el cuidadoso empeño con que mi Gobierno ha hecho efectiva la neutralidad de la República, impartiendo para tal objeto todus las ordenes e instrucciones que senian al caso, es to cierto que, inesperadamente, nos vimos sindicados de haber permitido violaciones ale esa netralidad, en obsequio de tno de esos beligerantes.

La ineulpación era absoluta y totaimente itfundada, pues jamás pudo pasăr por la mente del Gobierno ni de sus representantes en toda la extensión de nuestro territorio, la idea siquiera de comprometer $\mathrm{el}$ buen nombre $\mathrm{y}$ los intereses del poisi por efecto de actitudes ingratas a Ulyina de las potencias en hueha con las cuales el Ecuador mantiene relaciones amistosas. que todos nos enpeñamos en conservarm íntentar.

Afortunadamente, la inculpación $/ \mathrm{no} \mathrm{n}$ dia resistir a las demostraciones de la verdad; $y$ bastó que nuestra Carieillers exhibiege plerta y francamente la conducta del Gobierno, para que quedase desvanecida hasta la sombra de una incorreeción de parte nuestra.

De esa misma ocasión hubo de aprovechar nuestra Cancillería para restublecer el concepto de la rosición de la Repúbli(a en la comunidad internacional, como nación independiente $y$ soberana, pues no pudimos admitir que, para hacérsenos urta representación o reclanación, se buscrasce la intervención de un trreer Gobierno, como si hubiesemos estado sometidos a inesperada tutela.

La serie numerosa de los graves e inusitados incidentes marítimos a que ha dado lugar la Guerra Europea y que afectan vivamente los intereses, derechos y deberes de los paises neutrales, en sus reliciones con los beligerantes, incidentes que Jas Convenciones Internacionales no consultaban, han motivado hondas preocupaciones en los Gobiernos Americanos, entre los cuales ha habido un activo cambio de ideas, tendientes a buscar la nunera de amparar los intereses del Continente, sin lesionar derechos ajenos y teniendo en cuevta que no se ve clara la razón para que nucstros países sufran tan directamente las consecuencias de una guerra en la que ellos no son ni quieren ser parte.

Mi Gobierno ha concurrido a ese cambio de ideas, para cuyo efecto nucstra Cancillería ha impartido las instrucciones del caso a nuestro Representante en Washington, a quien se le insinu6 una proposicíón de acuerdo entre los países americanos. para que la sometiera a la consideración de los respectivos diplomáticos acreditidos en Fistados Lnidos de Norte America.

La costosísima experiencia que el mundo civilizado obtendrá de la gran Guerra Europea, darí lugar a trascendentales modificaciones del Derecho Internacional y acaso a nuevas convenciones, que definan taxativamente los deberes y derechos do los beligerantes y nentrales. Si este caso llega, debemos abrigar la esperanza de que las naciones americanas unirán sus esfuerzos en el propósito común de obtener las mayores garantías posibles para la guarda y respeto de su neutralidad y sus Oitereses, sin olvitar que el trabajo aislafonde tromo o varios de nuestros paises, joco o nada podra dar de ai; al paso que el enfuerro mancomunado de todas las namonssided continente, por su propia res-

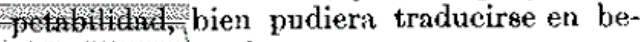
neficiosas cousquístas.

Jas consecuencias económicas de la Guerra Einopea rios han colocado en el caso de reducir nuestra representación dipoinatiea $y$ consular; $y$ el estado político consiguiente a esa misma guerra, ha inpuesto la postergación de numerosos Congresns y Conferencias Internacionales, a los cuales estábamos invitados y resueltos a asistir.

Nuestras diferencias limítrofes con la República del Perú debieran estarse al estatu-quo convenido; pero, desgraciadamente, mientras de unestra parte ha merecido respeto ineondicionat ese Convenio, no puedo informaros lo mismo respecto del Gobierno de ese pais amigo, pues, contrariabdo. a nuestro juicio, aquel Pacto, ha decretado eoncesiones de dercelios que afectan nuestra soberanía, en los territorios que se nos disputan y que nosotros los consideramos netamente ecuatorianos, por derccho, por tradición y por necesidad geográfica.

A esa actitud del Gobierno del Perú, el nuestro hat replicado protestando de aquellas concesiones y haciendo las debidas reservas, en guarda de nuestros derechos imprescriptibles, que no pueden estar subordinados a meros accidentes de hecho. 
El 17 de agosto de 1914, a 20 días de iniciada la guerra, Ecuador declaró su neutralidad. Esto se reiteró más tarde mediante un nuevo Decreto Ejecutivo de 28 de noviembre ${ }^{8}$ en el que se aprueba una serie de reglas -adicionales a la Convención de la Haya- para asegurar el "estricto mantenimiento de la neutralidad internacional". Estas medidas parecen condicionadas por la acusación que hizo Inglaterra que el gobierno de Ecuador había violado la neutralidad, se le acusó de que buques alemanes habían usado las islas Galápagos para aprovisionarse y que en Guayaquil había utilizado las comunicaciones inalámbricas ${ }^{9}$.

Posteriormente, en los primeros días de enero de 1915, se informó al gobierno que cerca del Archipiélago de Galápagos se encontraba el buque japonés "Kurama". Por ello se trasmitió una queja al Embajador de ese país, V. Chinda, "por el acto de permanecer en aguas territoriales del Ecuador por más de 24 horas, ignorando una formal notificación de abandonarlas dentro de ese término y sin ofrecer ninguna razón adecuada para ello"10.

Esta parece la razón para que en enero de 1915 se reafirme la neutralidad y se emita un nuevo Decreto con medidas, adicionales a las ya tomadas -y a las establecidas en la Convención de la Haya año de 18 de octubre 1907- para reiterar la neutralidad ecuatoriana ${ }^{11}$. Esto se complementa con la expedición del "Reglamento de visitas de buques de guerra extranjeros a puertos ecuatorianos" que se publicó el 26 de enero de $1917^{12}$.

El camino tomado por Gran Bretaña para su protesta fue solicitar a Estados Unidos que "remedie la situación, y que, de no hacerlo actuaría directamente, 'porque Galápagos tiene gran importancia para el pueblo del Ecuador' y ese pueblo, en consecuencia debe conocer lo sucedido"13.

El Presidente Plaza, en el informe al Congreso Ordinario de 1915, da a conocer estos eventos, sin referirse a los países involucrados y a los hechos concretos, y manifiesta su molestia por la forma en que se trató el tema:

8 RO No. 684 de 17 de diciembre de 1914

9 Alfredo Luna Tobar, Historia Política Internacional de las Islas Galápagos, Abya Yala, Quito, 1997, pp. 212 y sgts.

10 lbíd., p. 215

11 RO 715 de 26 de enero de 1915.

12 RO No. 120 de 26 de enero de 1917.

13 Alfredo Luna Tobar, Ob. Cit. p. 212. 


\section{La "Ley Moratoria" y medidas económicas}

En el Registro Oficial No. 557 de 7 de agosto de 1914, se publicó el Decreto Ejecutivo que dio origen a la mal llamada "Ley Moratoria". En esta, a pretexto de la Guerra, se "declara la inconvertibilidad de los billetes circulantes en oro; se prohíbe la emisión de más billetes y se crea una Comisaría de Bancos". Esto permitió que los bancos emitan grandes cantidades de dinero sin respaldo alguno. En resumen, no se permitía canjear los billetes, en los bancos, por su respaldo que era el oro.

Se consideró que esta fue una forma de favorecer, especialmente, al Banco Comercial y Agrícola de Guayaquil (de Francisco Urbina Jado), y a otras entidades bancarias, por la gran influencia que tenían en ese momento los bancos con el Gobierno al que habían otorgado varios créditos para enfrentar a la guerrilla del norte del país ${ }^{14}$. Inicialmente la decisión era temporal (30 días), pero se la mantuvo de forma indefinida (en realidad terminó en 1925).

La Ley se publicó en el Registro Oficial 595 de 31 de agosto de 1914, se suspendió el canje de billetes por oro, se emitieron nuevos billetes; el Estado garantizó el circulante; y se estableció un "Comisario" encargado de vigilar a los bancos.

\footnotetext{
14 "Napoleón Dillón es el más fuerte crítico y apunta directamente al Banco Comercial y Agrícola de Guayaquil de haber hecho emisiones sin respaldo y con complicidad del Gobierno atracaban al país. Víctor Emilio Estrada es el defensor de esta ley, de la que dice era la única forma de salvaguardar al reserva de oro del país, frente a la 1era Guerra Mundial (Además de la campaña contra la "Revolución Conchista". Frente a esta degradación de los liberales, convertidos en plutocráticos, surge como única respuesta nacional, un alzamiento de una liga de jóvenes militares al mando de Idelfonso Mendoza; se apresa a los pilares del régimen plutocrático, Leónidas Plaza y Francisco Urbina Jado. El espíritu de esta revolución es cívico, nacional y más que todo moralizador. Existe primero una junta militar, a la que sigue 6 meses después una junta cívica militar y posteriormente una Junta civil, un gobierno colegiado civil, y finalmente la dictadura civil de Isidro Ayora. Esta revolución fue la primera de carácter institucional (militar no caudillista) y al mismo tiempo significó la imposición de los intereses nacionales (en materia monetario-financiera) sobre los privados corporativistas y la institucionalización de la cuestión social, como política de Estado y no de gobierno. En la segunda Junta de Gobierno de la que fue parte Dillón, dictó una ley proteccionista para las nacientes industrias, forzó la aceptación de todos los billetes circulantes, creó el uso de patentes para los documentos negociables, fiscalizó y multó a los bancos que habían realizado sobre-emisiones y principalmente propuso y mediante ley creó el Banco Central del Ecuador, que era más bien una "Caja de Emisión Central de Emisión y Conversión"; sin embargo, en Guayaquil se da un movimiento "antijuliano" que incluso revive los fantasmas del federalismo y la autonomía, esto y la influencia de la bancocracia impidieron que se la ley entre en vigencia; y tuvo que esperarse que llegue la Misión Kemmerer, que fue contratada por los julianos y recibida bien por todos; esta después de cinco meses de su llegada en 1826 después de un trabajo profesional, en cinco meses propusieron las siguientes reformas constitucionales, legales y administrativas: Ley de Banco Central, Ley de Moneda, Ley General de Bancos, Ley de Presupuestos, Ley de aduanas y otros impuestos, Ley de creación de la Contraloría, Ley sobre Impuesto sobre la renta. Leónidas Plaza 1912-1916 Entre 1912 y 1925 gobernó el liberalismo burgués. Presidieron el Estado Leónidas Plaza (1912-1916), Alfredo Baquerizo (1916-1920), José Luis Tamayo (1920-1924) y Gonzalo Córdova (1924-1925). En julio de 1925 un golpe militar de tendencia progresista conocido como Revolución Juliana desplazó del poder al liberalismo burgués". Tomado de http://historiaecuador.blogspot.com/2005/12/revolucin-juliana-ii-instituciones.html, revisado el 5 de octubre del 2014.
} 


\section{Restricciones a las exportaciones ${ }^{15}$}

Una de las consecuencias de la conflagración fue la restricción de la exportación de ciertos productos agrícolas. El 13 de agosto de 1914, en Registro Oficial No. 581, se publicó el Decreto Ejecutivo por el cual se prohibió la exportación de productos de primera necesidad, excepto los productos de exportación (cacao, café y plátano de seda). Esta prohibición inicialmente fue de 30 días.

En mayo de 1916 se prohibió la exportación del azúcar ${ }^{16}$. Además, mediante Decreto de 13 de junio de $1916^{17}$, se prohibió la "exportación de moneda ecuatoriana de plata mientras dure la actual Guerra europea"18.

Tras el incremento de la demanda de azúcar ${ }^{19}$ y arroz como resultado del conflicto, el precio del azúcar tuvo un alza significativa en el mercado internacional y los productores privilegiaron su exportación. Ello provocó la escases de ese producto a nivel local ${ }^{20}$.

En febrero de 1917, por pedido del Concejo Cantonal de Guayaquil, se prohibió la exportación de trigo, maíz, lentejas, frejoles, cebada, arvejas y habas ${ }^{21}$. En julio se prohibió la exportación de arroz y se limitó la exportación de patatas $^{22}$.

El 30 de octubre de 1917 se emitió un Decreto Legislativo por el que se reformó la Ley Arancelaria de Aduanas ${ }^{23}$ que estableció una serie de restricciones a las exportaciones y a las importaciones. Con base en esa reforma, el 21 de noviembre de ese año, se derogaron las anteriores prohibiciones y se prohibió la exportación de los siguientes productos alimenticios: arvejas, habas, arroz, harina de toda clase, lentejas, cebada, maíz, frejoles, manteca, garbanzos, morocho, patatas, grasas, plátano dominico, trigo, otros cereales y legumbres. Otros artículos debían pagar el 40 \% por derechos de exportación ${ }^{24}$.

15 Una de las medidas que tomó el Gobierno fue la creación, a pedido de la Cámara de Comercio de Guayaquil, de una "Comisión Consultiva", compuesta por cinco miembros nombrados por el Ejecutivo, para "indicar la Ministro de Hacienda, las medidas que, en su concepto, deben ser adoptadas en todos y cada uno de los casos que se presenten con motivo de la precitada crisis". RO No. 607 de 14 de septiembre de 1914.

16 RO No. 1109 de 27 de mayo de 1916.

17 Especialmente por la expansión de la producción de azúcar de caña en detrimento del azúcar de remolacha.

18 RO No. 1126 de 17 de junio de 1916.

19 "[C]on motivo de la guerra el azúcar nacional ha escaseado notablemente en los mercados ecuatorianos, debido a la compra que se hace de él para llevarlo a plazas extranjeras, dado como consecuencia el alza inconsiderada de su precio".

20 GuerRero, RAFAEL, "Los ingenios en el desarrollo del capitalismo en el Ecuador 1900-1954", publicado en memorias del Segundo Encuentro de Realidad Histórica y Social del Ecuador", Universidad de Cuenca, Cuenca, 1978, pp. 527-616 (p.545), da cuenta de cómo se incrementó

21 RO No. 147 de 27 de febrero de 1917.

22 RO No. 250 de 4 de julio de 1917.

23 RO No. 346 de 30 de octubre de 1917.

24 RO No. 369 de 21 de noviembre de 1917. 


\section{Ruptura de relaciones con Alemania}

Luego que EEUU declaró la guerra a Alemania, en abril de 1917, algunos países también lo hicieron (Brasil, Guatemala, Costa Rica, Haití, Honduras, Cuba, Nicaragua y Panamá). Solo Brasil envío soldados (hundimiento Buque mercante Paraná, que tenía sus luces encendidas e identificación que acredite que era de país neutral). Los demás países enviaron soldados bajo bandera de EEUU o Francia. Algunos países permanecieron neutrales: Argentina, Chile, México, Colombia, Paraguay y Venezuela, El Salvador.

Bolivia, Perú, Uruguay y Ecuador rompieron relaciones con Alemania; esto fue visto como el desplazamiento de un "contexto hegemónico privilegiado, al cual se adscribió América Latina (salvo Centroamérica y el Caribe) [...] centrado en Europa, a otro: los Estados Unidos"25.

Nuestro país rompió relaciones con Alemania en diciembre de 1917.

En Presidente de la República Alfredo Baquerizo Moreno en su informe al Congreso Nacional, en agosto de 1917, defendió la neutralidad del Ecuador, afirmando que ${ }^{26}$ :

Nuestras relaciones con los demás países siguen en el mismo pie de cordialidad; nuestra neutralidad continúa, no sin que hayamos procurado una más ingenua y franca inteligencia con las Naciones todas del Continente Americano. Hemos manifestado nuestras simpatías y nuestra fe en toda ocasión en que la justicia lo exigía, o los grandes principios del régimen democrático, base y fundamento de estas nacionalidades, así lo requerían. América pues, nos encontrará siempre con ella. La Patria ecuatoriana es una de sus hijas, y la República su espíritu y su vida. Los Estados Unidos, a causa de las zonas de guerra en el mar, de la campaña de submarinos y de la consiguiente prohibición al comercio de los neutrales que todo ello implicaba, declaró la guerra al Imperio Alemán el 6 de abril de este año; y luego otras naciones como el Brasil y Bolivia, han roto sus relaciones con dicho Imperio o procedido en igual sentido que los Estados Unidos, como Cuba y Panamá. Nuestra actitud serena y amistosa, dentro de los límites de la neutralidad que habíamos adoptado, no dejó son embargo de dar margen a pequeños incidentes y a ciertas apreciaciones de suma ligereza, explicables en verdad por la actual tensión de los espíritus y la gigantezca [sic] lucha que lejos de tocar a su fin parece extender de día en día su acción, que alcanza en realidad, de una u otra manera, hasta los más apartados límites del

25 Vivas Gallardo, F., "Venezuela y la Primera Guerra Mundial. De la neutralidad al compromiso", p. 1.

26 RO No. 282 de 13 de agosto de 1917. 
mundo. No obstante esa actitud, igual a la de Colombia, Chile, Perú, Venezuela, entre otras del Continente, como el concepto de neutralidad viene modificándose con matices y procedimientos antes desconocidos en el derecho de gentes, conservándolo nosotros, no dejaremos de encontrarnos siempre y de preferencia con lo que exija nuestro deber democrático, nuestro deber republicano y nuestro deber de hijos de América.

De esta Cancillería fue la insinuación de un Congreso de Neutrales, acogida con benevolencia por casi toros los países de América; y aceptamos luego la invitación que nos hizo la Argentina con idénticos fines. Los acontecimientos posteriores y el cambio de situación internacional en algunas República, ha impedido o demorado hasta ahora esa reunión que habría contribuido sin duda alguna a dar fuerza y vigor a principios de justicia y neutralidad y a definir claramente la posición del continente en el grande y pavoroso conflicto cuyos comienzos arrancan de agosto del año catorce.

Como se puede ver, pese al discurso de neutralidad, es posible intuir una justificación a la decisión de los Estados Unidos de declarar la guerra, así como una clara simpatía ante la causa "Americana". En el siguiente informe al Congreso, año 191827 , el Presidente explicó la ruptura de las relaciones con Alemania en los siguientes términos:

En Diciembre último quedaron rotas nuestras relaciones diplomáticas con el Imperio Alemán. Durante las sesiones de 1917 el Congreso tuvo ya conocimiento de nuestra negativa a recibir al Ministro señor Pearl, negativa que desde luego implicaba una suspensión o interrupción en el trato diplomático. La actitud del señor Müller, y el deber de un procedimiento revelase nuestra actitud solidaria en muchos países de América sostenedores, en una u otra forma, de igual y aún más avanzadas declaraciones de política internacional, nos parecieron motivos suficientes en sí, para que el Ecuador, país de hondo ráiganme democrático y de instituciones francamente liberales, procediera como dejo indicado.

Esta posición contrataba con la actitud amistosa y cordial con Francia:

El 21 de julio llegó a esta Capital la Misión presidida por Sir Maurice de Bunsen en su carácter de Embajador Extraordinario y Plenipotenciario en Misión Especial. Fué [sic] recibida en el mismo día con los honores y la cordialidad debidos a tan alta y distinguida representación, y se despidió el 23 en la mañana, la Embajada viene recorriendo las Capitales de América del Sur, en misión de paz, cortesía y amistad. 
Manifesté la simpatía del pueblo y Gobierno ecuatorianos a la vieja y heroica Francia [...]

Es tan notoria la preferencia a partir de la ruptura de relaciones que mediante Decreto Ejecutivo se declaró el 14 de julio de 1918 como "fiesta cívica nacional". El texto de los considerandos lo revela de manera evidente ${ }^{28}$ :

Que las sinceras relaciones de amistad y simpatía que existen entre el Ecuador y Francia, y el significado que en todo tiempo ha tenido y tiene, especialmente ahora, la fecha nacional de esa noble y heroica República, son causa suficiente para que se considere en la actualidad como propia la celebración de esta fiesta.

La misma consideración y amistad se tuvo hacia los Estados Unidos. Un buen ejemplo de esto es el telegrama que se envió a ese país con motivo de la "Fiesta de la Raza". De acuerdo a la propuesta aprobada, por unanimidad, en sesión plena de Congreso Nacional (Senado y Cámara) el 13 de octubre de $1918^{29}$, se debía enviar:

[...] mensajes cablegráficos, por conducto de la Cancillería, a todas las Naciones de raza latina de Europa y América [...]. A la República de los Estados Unidos de Norte América se enviará otro mensaje especial y congratulándole por su actitud serena y altruista en defensa de la causa de la Justicia y de los derechos de la Humanidad.

Es obvio que, como consta en los informes al Congreso, los principales mercados comerciales de Ecuador eran, para los años de la ruptura de relaciones, España y Estados Unidos. En cuanto a la admiración que se profesaba a Francia esta se puede entender en gran medida por la posición adoptada por el Ecuador.

\section{IV. iViva la paz! iGanamos la Guerra!}

Inmediatamente recibida la noticia del fin de la guerra en el Ecuador, 11 de noviembre de 1918, se emitió el Decreto No. 4230 , por el que se declaró al 12 de noviembre "como fiesta de la paz universal, que debe celebrarse por la República". En los considerandos del Decreto se justifica así esa decisión:

Que la cesación de hostilidades de la guerra mundial es el principio del restablecimiento de la paz, del concierto y armonía universales, suceso 
que debe ser mirado con justo regocijo por todas las clases sociales, puesto que dicho restablecimiento será de imponderables consecuencias para el bienestar de todos los hombres y pueblos de la tierra.

Sin embargo, el documento que mejor refleja la reacción del país ante el fin de la guerra es el mensaje del Presidente Baquerizo Moreno al Congreso Ordinario del año $1919^{31}$, en este se presentó al Ecuador como parte de los vencedores:

Me complazco en saludaros esta vez cuando la paz impera ya en el mundo, y cuando esa paz significa, además, que ha llegado la hora de la tranquilidad de los débiles y de la igualdad entre los hombres y los pueblos -igualdad de Derecho, se entiende- con sólo una justicia para todos y una misma e inviolable libertad.

Nuestra actitud en los días oscuros y trágicos de la lucha, nos dio luego, en la paz de la victoria, asiento señalado en las Conferencias de Versalles.

Lo relativo al Tratado con Alemania, como fin de la guerra, puede decirse no es extraño, en el sentido de no haber tomado nosotros, el carácter de beligerantes [...].

Finalmente el Presidente se refirió al proyecto de una "Liga de las $\mathrm{Na-}$ ciones", que considera algo digno de atención, así como la idea que triunfaron los pueblos que defienden a la democracia:

La democracia también quedó a salvo y al parecer asegurada con el derrumbamiento de los imperios y organismos seculares contrarios evidentemente, a la evolución democrática y social que viene desenvolviéndose de tiempo atrás; la cual, con el triunfo de los pueblos que lo han representado desde mucho antes, irá adelante, como una marea viva, irresistible, de progreso, cultura y bienestar.

\section{A manera de conclusión:}

La Primera Guerra Mundial tuvo un fuerte impacto en el país, especialmente en materia económica, que perduró durante muchos años luego que terminara. La llamada "Ley Moratoria" fue derogada apenas en 1925 como efecto de la Revolución Juliana, pero contribuyó a un ambiente de descontento social relevante y a la configuración de la futura moneda del Ecuador. 
Desde el punto de vista de las relaciones internacionales, el conflicto significó el desplazamiento de la hegemonía europea en lo social, lo económico y lo político, a los Estados Unidos, que a partir de ese momento cobró un rol de potencia hegemónica frente a nuestro país. 